\title{
Pitfalls in endosonographic imaging of suspected insulinomas: pancreatic nodules of unknown dignity
}

\author{
P H Kann, B Wirkus, A Keth and K Goitom \\ Division of Endocrinology and Diabetology, Clinic for Gastroenterology, Endocrinology and Metabolism, Centre for Internal Medicine, \\ Philipps University Medical School, D-35033 Marburg, Germany
}

(Correspondence should be addressed to P H Kann; Email: Kannp@med.uni-marburg.de)

\begin{abstract}
Objective: Endosonography enables localization and characterization of gastroenteropancreatic neuroendocrine tumors. We have studied the problem of misleading abnormalities of pancreatic morphology as obtained by endosonographic imaging.

Design and methods: A total of 438 endosonographies performed for known or suspected diseases of the adrenal glands and/or the pancreas and/or suspected metastases in the neighboring tissues were analyzed.

Results: In the pancreas, nine benign insulinomas, four non-metastatic islet cell carcinomas, and multiple benign neuroendocrine tumors in one patient with multiple-endocrine neoplasia-1 (MEN-1) disease were detected and correctly localized as proven by postoperative histology. In three further patients with genetic diagnosis of MEN-1, asymptomatic tumors were detected and are under observation. However, we also found an $8 \times 4 \mathrm{~mm}$ hypoechoic tumor in the cauda pancreatis of a patient with severe factitial hypoglycemia (glimepiride). In another patient suffering from severe hypoglycemia, a hypoechoic area of $24 \times 10 \mathrm{~mm}$ in the processus uncinatus/caput pancreatis was found. Although organic hyperinsulinism was excluded, this patient underwent surgery because of suspected pancreatic carcinoma. There was normal pancreatic tissue in the abnormal region, which was also localized by intraoperative sonography. In a third patient with an adrenal carcinoma, a $6 \times 3 \mathrm{~mm}$ hypoechoic nodule in the cauda pancreatis did not change its morphology over an observation period of 13 months, its clinical relevance is completely unclear.

Conclusions: Pancreatic nodules of unknown dignity were detected in nearly $1 \%$ of our patients and must be considered to be a diagnostic problem. These experiences clearly show, on the one hand, that pancreatic endosonography is a very useful diagnostic support in the management of endocrine tumor patients. However, on the other hand, endosonography of endocrine organs is not a substitute for careful endocrinological examination and testing and must be considered in the context of endocrinological findings.
\end{abstract}

European Journal of Endocrinology 148 531-534

\section{Introduction}

Endosonography performed via the stomach and the duodenum is an established diagnostic approach in pancreatic diseases. In gastroenterology, it is mainly used for detection and staging of pancreatic adenocarcinomas, inflammatory diseases, and their sequelae $(1-13)$.

In addition, endosonography is considered more and more to be a useful diagnostic tool in endocrinology. The resolution is much better than by computed tomography and magnetic resonance imaging. Thus it enables detection and localization of even small neuroendocrine tumors. Its use in endocrinology for imaging of the adrenal glands and the endocrine pancreas is therefore becoming more frequent (14-18). However, compared with pancreatic adenocarcinomas, neuroendocrine tumors of the pancreas are not very frequent. Only small series or single cases have been published (18-23).

Patients typically presenting to a department of endocrinology are those with symptomatic hypoglycemia suspected of suffering from an insulin-secreting neuroendocrine tumor, i.e. insulinoma or islet cell carcinoma. In this study, we have addressed the problem of misleading abnormalities of pancreatic morphology as obtained by endosonographic imaging.

\section{Subjects and methods}

In order to consider the problem of misleading abnormalities of pancreatic morphology by endosonographic imaging, a total of 438 endosonographies performed for known or suspected diseases of the adrenal glands and/or the pancreas and/or suspected metastases in the neighboring tissues were analyzed. 
All examinations were performed by the same experienced investigator following a standardized operation procedure including careful examination of both adrenal glands and the pancreas.

Endosonography was performed using a Pentax FG 32 UA endosonoscope with a longitudinal $7.5 \mathrm{MHz}$ sector array in combination with Hitachi EUB 420 or Hitachi EUB 525 ultrasound computers (Hitachi Medical Corp., Tokyo, Japan). Informed consent was obtained from each patient. Premedication was performed with $30 \mathrm{mg}$ pentazocine, $10-30 \mathrm{mg}$ diazepam, and $0.25-0.5 \mathrm{mg}$ atropine. Examination time was approximately $45 \mathrm{~min}$.

\section{Results}

In the pancreas, nine benign insulinomas, four nonmetastatic islet cell carcinomas, and multiple benign neuroendocrine tumors in one patient with multiple endocrine neoplasia-1 (MEN-1) disease were detected, localized and correctly identified as proven by postoperative histology.

In three further patients with genetic diagnosis of MEN-1, asymptomatic tumors were detected and are under observation without surgical treatment.

In pursuit of the aims of this study, in three cases misleading abnormalities of the pancreas (prevalence $0.7 \%$ ) were found.

\section{Case 1}

A 45-year-old male was examined because of recurrent severe symptomatic hypoglycemia. A fasting test $(72 \mathrm{~h})$ was positive: blood glucose concentration was decreased to $29 \mathrm{mg} / \mathrm{dl}$. At the same time, insulin and c-peptide serum concentrations were inadequately high: $11.7 \mu \mathrm{U} / \mathrm{ml}$ and $3.7 \mathrm{ng} / \mathrm{ml}$ respectively. By endosonographic imaging of the pancreas, an $8 \times 4 \mathrm{~mm}$ hypoechoic tumor in the cauda pancreatis was detected (Fig. 1). Computed tomography detected a suspect

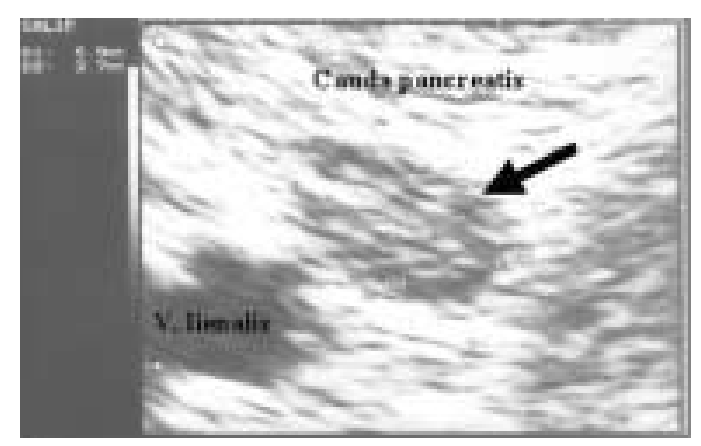

Figure 1 Case 1: hypoechoic tumor $(8 \times 4 \mathrm{~mm})$ in the cauda pancreatis of a patient with severe hypoglycemia where glimepiride was detected in urine and serum samples. After diagnosis of factitial hypoglycemia, this patient refrained from a follow-up control of this abnormality. formation in the same region of the pancreas which, however, did not show enhancement during the arterial phase of contrast medium application. Surprisingly, glimepiride was detected in urine and serum samples (serum concentration at the time of minimum blood glucose concentration was $474 \mathrm{ng} / \mathrm{ml}$ ). The patient's wife suffered from type 2 diabetes and received glimepiride treatment. Following a long exploration, our patient admitted to the intake of glimepiride. After diagnosis of factitial hypoglycemia, this patient left the hospital and refrained from a follow-up control of his pancreatic abnormality. According to information provided by the patient's general practitioner no further episodes of hypoglycemia occurred.

\section{Case 2}

Another male patient (67 years old) suffered from recurrent episodes of symptomatic hypoglycemia. Organic hyperinsulinism was not proven by a 72 -h fasting test. An oral glucose tolerance test provided evidence for carbohydrate-induced reactive hypoglycemia (minimum blood glucose level $39 \mathrm{mg} / \mathrm{dl}$, suppressed insulin and c-peptide secretion). By endosonographic imaging, a hypoechoic area of $24 \times 10 \mathrm{~mm}$ was found in the processus uncinatus/caput pancreatis (Fig. 2). This patient underwent surgery since the morphologic abnormality in the pancreas was also detected by computed tomography and considered to be typical for a small pancreatic carcinoma. Histologically, there was normal pancreatic tissue in this abnormal region, which was also detected and localized by intraoperative sonography.

\section{Case 3}

A female patient (50 years old) underwent retroperitoneal endosonography for postoperative restaging after surgical therapy of left adrenocortical carcinoma. There was no evidence for hypoglycemia in the

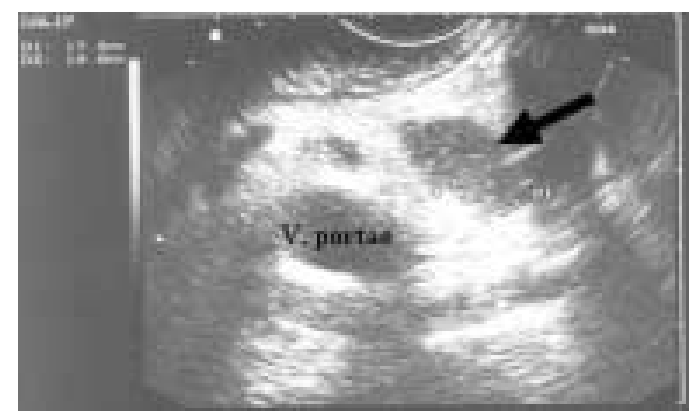

Figure 2 Case 2: hypoechoic area $(24 \times 10 \mathrm{~mm})$ in the processus uncinatus/caput pancreatis in a patient suffering from severe hypoglycemia. Although organic hyperinsulinism was not proven, this patient underwent surgery. There was normal pancreatic tissue in the abnormal region which was also localized by computed tomography and intraoperative sonography. 


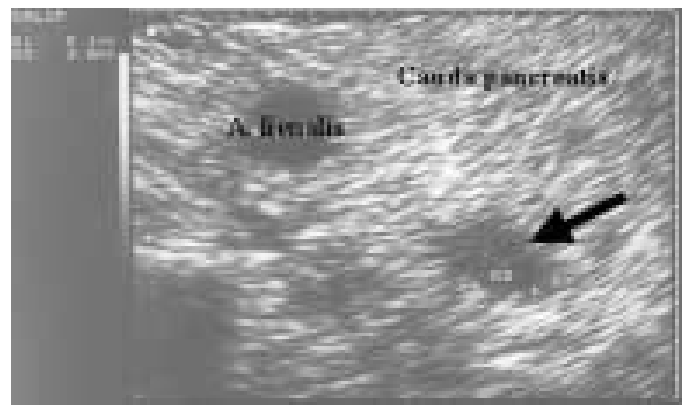

Figure 3 Case 3 : hypoechoic nodule $(6 \times 3 \mathrm{~mm})$ in the cauda pancreatis in a patient with an adrenal carcinoma which did not change its morphology over an observation period of 13 months. Its clinical relevance is unclear.

patient's history or in the laboratory findings. In this patient, a $6 \times 3 \mathrm{~mm}$ hypoechoic nodule in the cauda pancreatis was detected by endosonographic imaging (Fig. 3). This finding could not be confirmed by computed tomography or magnetic resonance imaging but was, however, reproducible by re-endosonography. Its morphology remained unchanged over an observation period of 13 months. Its clinical relevance is completely unclear.

\section{Discussion}

Neuroendocrine tumors of the pancreas are rare. Some may cause typical gastrointestinal symptoms such as recurring and multiple peptic ulcers or severe diarrhea due to hormone production influencing intestinal secretion and/or motility. Large clinically hormone inactive tumors with or without hepatic metastases may cause abdominal discomfort/pain, symptoms of intestinal obstruction, nausea and/or other unspecific epigastric symptoms. Usually, these patients are referred to a gastroenterologist for diagnostic evaluation. In their hands, upper gastrointestinal endosonography has been established as a useful diagnostic tool for a number of years (23).

Other patients with neuroendocrine pancreatic tumors are usually evaluated and diagnosed by endocrinologists. These are, in particular, patients with suspected organic hyperinsulinism causing symptomatic hypoglycemia. Until recently, the strategy in these patients was to confirm organic hyperinsulinism by standardized endocrine testing, especially a 72-h fasting test. Thereafter, they were referred to an experienced surgeon who localized the tumor using intraoperative ultrasound and/or palpation of the pancreas after laparotomy. Localization of the tumor was not considered to be mandatory and thus has not been performed systematically (24).

Nowadays, the situation has changed because different techniques of endoscopic pancreatic surgery have been introduced (25-27). Endoscopic enucleation or selective resection of a neuroendocrine tumor in the pancreas can only be performed, however, if this tumor can be localized exactly if it can be confidently decided whether this is a uni- or multilocular disease, and when there is no evidence for malignancy.

Under these conditions, preoperative imaging becomes important in planning therapeutic strategy. Endosonography seems to be a very sensitive tool in this context (18).

However, it must be considered that endosonographic imaging of the pancreas can yield misleading findings. In 438 endosonographic examinations, pancreatic nodules of unknown dignity (PNUDs) were seen in nearly $1 \%$. In two of our three cases, computed tomography also detected suspect abnormalities in the same location.

PNUDs must be considered as a diagnostic problem. In two of our three cases, these were not simply 'pancreatic incidentalomas' but were, in fact, misleading morphologic abnormalities, since these patients were investigated by endosonography in order to detect and localize a pancreatic tumor.

The experiences with endosonography in diagnosing neuroendocrine pancreatic tumors clearly show that, on the one hand, pancreatic endosonography is a very useful diagnostic support in the management of patients with endocrine tumors, especially in planning surgical strategy (18). However, on the other hand and as our recent findings show, endosonography of endocrine organs cannot be a substitute for careful endocrinological examination and testing and must be considered in the context of clinical conditions and endocrinological findings.

\section{Acknowledgements}

This study was supported by the Foundation for Innovation of Rhineland-Palatinate. Important parts of this study were performed at the I. Medical Department, Johannes Gutenberg University Hospital, Mainz, Germany.

\section{References}

1 Dancygier H. Endoscopic ultrasonography in chronic pancreatitis. Gastrointestinal Endoscopy Clinics of North America $1995 \mathbf{5}$ 1052-1057.

2 Devière J, Finet L, Dunham F \& Cremer M. Endoscopic ultrasonography in chronic pancreatitis. Endoscopy $199426808-809$.

3 Grimm H, Mayendo A \& Soehendra N. Endoluminal ultrasound for the diagnosis and staging of pancreatic cancer. Bailliere's best practice and research. Clinical Gastroenterology $1990 \mathbf{4}$ 869-888.

4 Lees WR. Endoscopic ultrasonography of chronic pancreatitis and pancreatic pseudocysts. Scandinavian Journal of Gastroenterology 198621 123-129.

5 Müller MF, Meyerberger C, Bertschinger P, Schaer R \& Marincek B. Pancreatic tumors: evaluation with endoscopic US, CT, and MR imaging. Radiology 1994190 745-751.

6 Nattermann C \& Dancygier H. Endosonographie bei Tumoren des Pankreas und der Gallenwege. Leber Magen Darm 19931 13-23. 
7 Nattermann C, Goldschmidt AJW \& Dancygier H. Endosonography in chronic pancreatitis - a comparison between endoscopic retrograde pancreatography and endoscopic ultrasonography. Endoscopy 199325 565-570.

8 Nattermann C, Goldschmidt AJW \& Dancygier H. Endosonographie in der Dignitätsbeurteilung von Pankreastumoren. Deutsche Medizinische Wochenschrift 1995120 1571-1576.

9 Rösch T, Lorenz R, Braig C, Feuerbach S, Siewert JR \& Classen M. Endosonographische Diagnostik bei Pankreastumoren. Deutsche Medizinische Wochenschrift 1990115 1339-1347.

10 Wiersema MJ, Hawes H, Lehmann GA, Kochmann ML, Sherman S \& Kopecky KK. Prospective evaluation of endoscopic ultrasonography and endoscopic retrograde cholangiopancreatography in patients with chronic abdominal pain of suspected pancreatic origin. Endoscopy 199325 555-564.

11 Wiersema MJ \& Wiersema LM. Endosonography of the pancreas: normal variation versus changes of early chronic pancreatitis. Gastrointestinal Endoscopy Clinics of North America $1995 \mathbf{5}$ 487-496.

12 Yasuda K, Mukai H, Fujimoto S, Nakajiama M \& Kawai K. The diagnosis of pancreatic cancer by endoscopic ultrasonography. Gastrointestinal Endoscopy $1988 \mathbf{1 3 4} 1-8$.

13 Zuccaro G Jr \& Sivak MV Jr. Endoscopic ultrasonography in the diagnosis of chronic pancreatitis. Endoscopy 199224 347-349.

14 Kann P, Bittinger F, Hengstermann C, Engelbach M \& Beyer J. Endosonographische Darstellung der Nebennieren: Eine neue Methode. Ultraschall in der Medizin 199819 4-9.

15 Kann P, Hengstermann C, Heussel CP, Bittinger F, Engelbach M \& Beyer J. Endosonography of the adrenal glands: normal size pathological findings. Experimental Clinical Endocrinology and Diabetes $1998106123-129$.

16 Kann P, Heintz A, Bittinger F, Herber S, Kunt T \& Beyer J. Endosonographie bei kleinen Nebennierenraumforderungen: Morphologischer Nachweis der mikro- und makronodulären Nebennierenrindenhyperplasie in vivo als Ursache einer autonomen Sekretion von Steroidhormonen. Tumordiagnostik und Therapie 199920 135-143.

17 Kann P, Heintz A, Bittinger F, Kessler S, Forst T, Weis A et al. Bildgebende Diagnostik der Nebennieren: neue Aspekte durch die Einführung der Endosonographie. Minimal invasive Chirurgie $2000958-61$.

18 Kann P, Bittinger F, Engelbach M, Bohner S, Weis A \& Beyer J. Endosonography of insulin-secreting and clinically non-functioning neuroendocrine tumors of the pancreas: criteria for benignancy and malignancy. European Journal of Medical Research 20016 385-390.

19 Bolondi L, Li Bassi S, Gaiani S, Campione O, Marrano D \& Barbara L. Diagnosis of islet cell tumor by means of endoscopic ultrasonography. Journal of Clinical Gastroenterology 199012 212-218

20 Lightdale CJ, Botet JF, Woodruff JM \& Brennan MF. Localization of endocrine tumors of the pancreas with endoscopic ultrasonography. Cancer 199168 1815-1820.

21 Meyenberger C, Bertschinger P, Zala GF \& Marincek B. Endosonography in diagnosis of insulinoma. Ultraschall in der Medizin 1995 $16224-227$.

22 Scheffold N, Arnold R \& Cyran J. Metastasierendes PankreasVipom. Deutsche Medizinische Wochenschrift 1995129 1463-1466.

23 Zimmer T, Ziegler K, Liehr RM, Stolzel U, Riecken EO \& Wiedenmann B. Endosonography of neuroendocrine tumors of the stomach, duodenum, and pancreas. Annals of the New York Academy of Sciences $1994 \mathbf{7 3 3}$ 425-436.

24 Daggett PR, Goodburn EA, Kurtz AB, Le Quesne LP, Morris DV, Nabarro JD et al. Is preoperative localisation of insulinomas necessary? Lancet 19811 483-486.

25 Arca MJ \& Gagner M. Minimally invasive procedures of the pancreas. Chirurg $199869621-627$.

26 Dexter SP, Martin IG, Leindler L, Fowler R \& McMahon MJ. Laparoscopic enucleation of a solitary pancreatic insulinoma. Surgical Endoscopy 199913 406-408.

27 Underwood RA \& Soper NJ. Current status of laparoscopic surgery of the pancreas. Journal of Hepatobiliary and Pancreatic Surgery $19996154-164$.

Received 31 October 2002

Accepted 25 February 2003 